\title{
Microstructure Evolution of Grade X100 Pipeline under Plastic Deformation Condition
}

\author{
Lihua Qi, ${ }^{1,2}$ Long Yang, ${ }^{1}$ Jing Niu, ${ }^{1,2}$ Yaorong Feng, ${ }^{1}$ and Jianxun Zhang ${ }^{2}$ \\ ${ }^{1}$ Tubular Goods Research Center of CNPC, Shan'Xi 710065, China \\ ${ }^{2}$ Schools of Materials Science and Engineering, Xi'An Jiaotong University, Shan'Xi 710049, China
}

Correspondence should be addressed to Lihua Qi, qlh1973@163.com

Received 30 July 2010; Revised 1 November 2010; Accepted 13 December 2010

Academic Editor: Pavel Lejcek

Copyright ( 2010 Lihua Qi et al. This is an open access article distributed under the Creative Commons Attribution License, which permits unrestricted use, distribution, and reproduction in any medium, provided the original work is properly cited.

\begin{abstract}
The effects of plastic deformation on the microstructure evolution of grade X100 pipeline were investigated by SEM, TEM and EBSD tests. The result shows that quasipolygon ferrite deforms firstly under plastic strain initial stage, then both acicular ferrite and granular bainite change remarkably with the value of plastic strain increase. When the tension stress reaches the tensile strength, microcracks nucleate around the inclusion and M/A constitute, expand with the plastic deformation increases, and finally cracks connection causes the crack penetration until the expiration. Furthermore, the microscopic orientation concentrates in $\{110\}\langle 111\rangle$ direction before the deformation, while crystal orientation in $\{110\}$ and $\{112\}$ direction enhanced after the deformation.
\end{abstract}

\section{Introduction}

At present, requirement for natural gas is rapidly increasing internationally. Pipeline is used for crude oil and natural gas transmission over long distance. Recent researches indicated that there are significant advantages of using higher grade line pipes, such as X100 even X120 grade pipeline, in constructing long distance pipeline, because it can improve transportation efficiency of the natural gas pipelines by increasing internal transportation pressure, and material cost can be saved correspondingly by reducing wall thickness of pipe body and consumable for girth welding [1-5]. However, there are still many transportation safety problems laying high strength pipelines. First of all, due to line pipes laid through complicated regions, such as earthquake region with high-risk, gas pipelines in service may endure large displacement and stress. Secondly, It was reported that the crosswise strain rate of UOE pipeline achieves $2 \%$ in the manufacture process, and the maximum flexure deformation at part of the pipeline reaches to $4 \% \sim 5 \%$ when it lays through multiple-region of earthquake and geology casualty [6-10]. Thirdly, there are a lot of natural gas let-out or exploration accidents due to pipeline plastic fracture in the world. Therefore, in order to guarantee property stability and operational safety of the pipeline, it is necessary to research the microstructure evolution mechanism under plastic deformation condition. In this paper, the grade X100 pipeline microstructure and texture transformation were investigated during the in situ plastic tensile process.

\section{Experimental}

Metallographic, SEM, EBSD, and TEM experiments samples were prepared at $1 / 4$ thickness position of the pipelines steel, which ingredients (w\%) are C 0.064, Si 0.095, Mn 1.69, Cr 0.013, Mo 0.031, Ni 0.2, Nb 0.042. In situ SEM specimens were prepared at the $1 / 4$ thickness position of the pipeline steel and processed to $1.0 \mathrm{~mm}$ thickness by linear cutting machine, as shown in Figure 1. The specimen was polished and etched with $2 \% \mathrm{HNO}_{3}+98 \%$ alcohol for 20 seconds. The specimen was placed on JSM-5800 stretcher to observe microstructure transformation, crack initiation, and expansion through controlling load-on velocity.

In order to observe the dislocation transformation and subgrain formation, the specimens were performed $1 \%, 2 \%$, $3 \%$, and $5 \%$ prestrain. Then the tested specimen was cut into $0.3 \mathrm{~mm}$ thickness by linear cutting machine to make the TEM specimen and was reduced below $50 \mu \mathrm{m}$ on MTP21A instrument and observed by H-800 TEM instrument. 


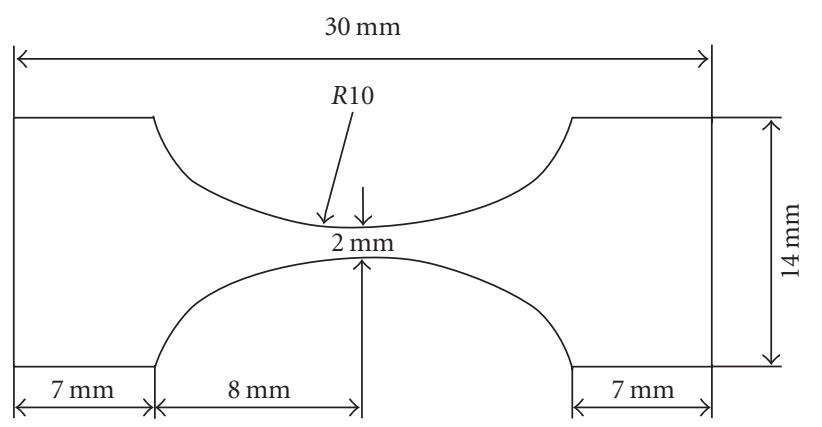

FIGURE 1: Schematic picture of in situ SEM specimens.

\section{Results}

3.1. Microstructure Deformation. SEM, TEM picture and diffraction pattern of the grade X100 pipelines microstructure are shown in Figure 2. It is consisted of acicular ferrite, granular bainite, M/A constituents (a mixture of martensite plus retained austenite), and little of quasipolygon ferrite. The acicular ferrite grain is fine and is uniformly distributed, which increase yield strength and tensile strength of the grade X100 pipeline. At the same time, lots of M/A particles laid uniformly in crystal grain and on the granular bainite boundary; it makes the microstructure of the X100 pipeline with excellence toughness. The ferrite plank (length) the axial ratio is about $3: 1$. The morphology of $\mathrm{M} / \mathrm{A}$ constitute in ferrite plank boundary is strip-shaped or island-shaped, and the size is about $50 \mathrm{~nm}$, as shown in 1,2 and 3 regions of Figure 2(b). A large number of high density dislocations were distributed around the M/A constituents and interior ferrite plank. High density dislocation morphology assumes tangle or grid configuration. This kind of tangled or the existence node's dislocated grid configuration is advantageous to the dislocation stabilization, as in Figure 2(b) [11]. Figure 2(c) is the ferrite and M/A constitute diffraction pattern of the Figure 2(b) 1 region. According to the TEM picture of the microstructure, it is proved that the M/A constitute is mainly composed of high carbon martensite, no twin martensite, and some retained austenitic, which suggested that base structure has well toughness.

When the tensile strain is applied on the both ends of specimen, the microstructure morphology change at the surface of specimen can be studied with the strain increase. At this time, tensile stress reaches to $1200 \mathrm{~N}$, as shown in Figure 4 arrow 1. Slip deformation was observed primitively in the crystal grain of quasipolygon ferrite, as shown in Figure 3(a) A region. The TEM picture of the quasipolygon ferrite after plastics deformation is shown in Figure 3(c). It is obvious that quasipolygon ferrite plank size is larger slightly than that of acicular ferrite and granular bainite, while the dislocation density of it is remarkably lower. Therefore, the tensile strength of the quasipolygon ferrite is lower than that of others; the ferrite plank boundary becomes prolonged and flexural after plastic deformation. Dislocation accumulated and dislocation density increased. Subsequently, when the plastic deformation increases, just as in Figure 4 arrow 2, big grain sizes of acicular ferrite and granular bainite slipped deformation gradually, as shown in Figure 3(b) arrow 1, and the deformation also emerged between the deformation bainite and the neighboring acicular ferrite crystal grain, as in Figure 3(b) arrow 2. From the TEM picture of grade X100 pipeline after $2 \%$ strain, it can be observed that the ferrite planks elongate along the drawing direction, and the subgrain appeared in the plank, as shown in Figure 3(d). At the time, bulges appear on the surface of the distortion larger grain size of granular bainite and the acicular ferrite. But there is no obvious distortion in the region of small granular bainite crystals gathered together and it maintains the original shape. It displays the good antiplastic deformation ability, see Figure 3(b) region.

Granular bainite microstructure transformation pictures before and after plastic deformation are shown in Figure 4. When the amount of plastic deformation further increases, approach tensile strength, as arrow 3 of Figure $4(\mathrm{~d})$. The tension stress is still increased but the growth rate reduced gradually; both tiny acicular ferrite and the bainite crystal grain have been deformed. It is clear that the tension stress grown slowly with the plastic deformation increase, and the big grain size of ferrite deformed in the first place. When the deformation further increased, coordinated deformation happened between the acicular ferrite and the granular bainite crystal grain, and the bugles raised on the surface of big size deformation crystal, just as mentioned before. The grain boundary of ferrite and bainite also has the bending deformation along with it, just as shown in arrows of Figure 4(c); however, the original austenite crystal boundary was still invariable, see Figure 4(b) arrow 1. The distortion range of the small grain size of acicular ferrite and granular bainite is small, as shown in Figure 4(b) A place. With stress further enlargement, the entire crystal grain surface presents bugles, and it cannot distinguish basically out the original austenite crystal boundary, as shown in Figure 5(a).

3.2. Formation and Expansion of Microcrack. Figure 5 is the picture of microcrack formation and expansion. During the stretches process, when the tension stress reaches the tensile strength, the tensile strength number no longer increases, but the test specimen still has slow plastic deformation. Furthermore, the quasipolygon ferrite has occurred distorts greatly; both the granular bainite and the acicular ferrite in the original austenite crystal interior were deformed along the stretch direction. However, since both M/A constitute and oxide compound inclusion possessed high intensity and are not easy to distort, there are a large number of stress concentrations around them after plastic deformation. When the stress concentration attains some extent, the substrate organization and M/A constitute separated gradually with tensile deformation's increase. It becomes the nucleus core of microcrack, as in Figure 5(a) arrows 1 and 2, Figure 4(b) arrow 2, and Figure 5(b) is the crack enlargement picture.

Along with deformation further increase, the microcrack expanded rapidly, connected, and formed the macroscopic transgranulation crack. Simultaneously, the tension stress rapidly reduces, and the deformation speed suddenly increases, until test specimen breaks. Figure 6 is the picture of the macroscopic crack formation and the enlargement 


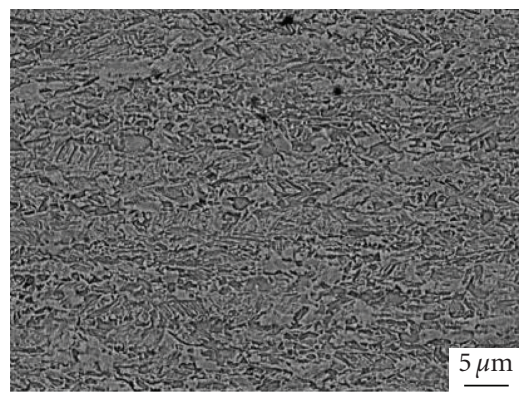

(a)

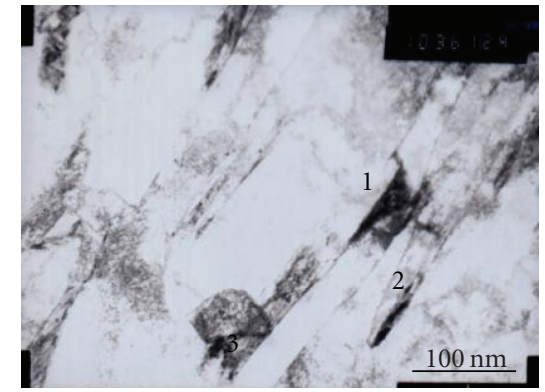

(b)

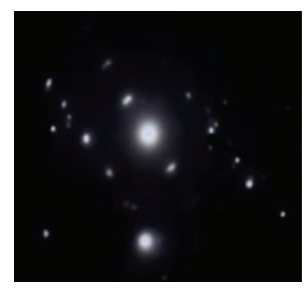

(c)

FIGURE 2: SEM and TEM pictures of grade X100 pipelines of metallurgical structure (a) and (b) and diffraction pattern of ferrite and M/A constitute (c).

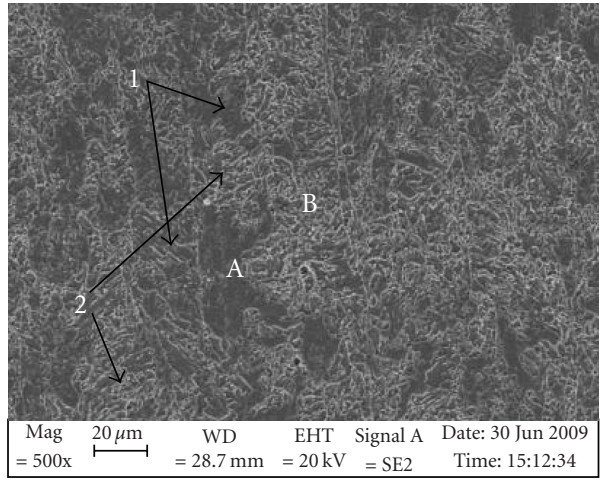

(a)

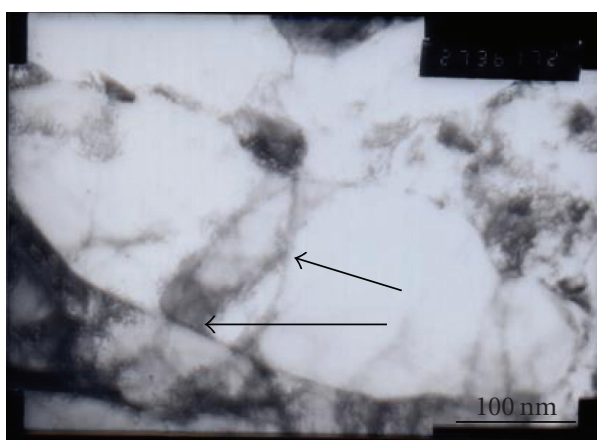

(c)

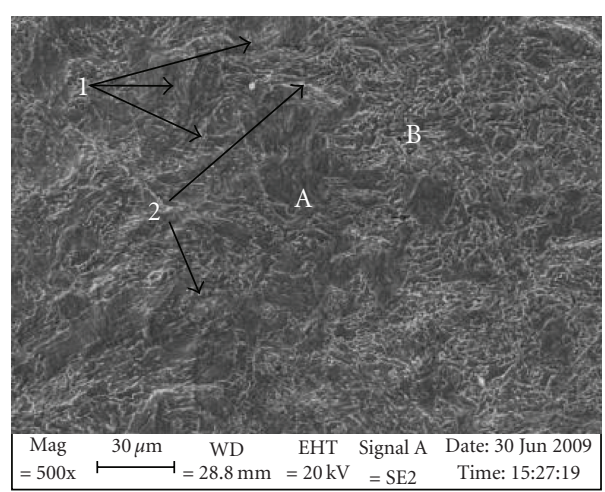

(b)

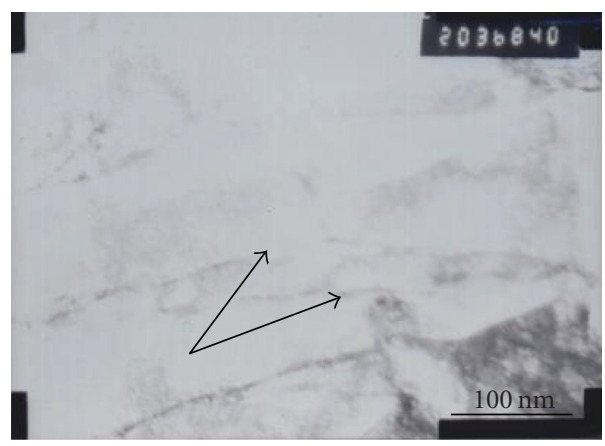

(d)

FIGURE 3: SEM and TEM pictures of quasipolygon ferrite microstructure transformation (a) original (b), (c), and (d) after tensile.

picture. It can be observed that the inclusion becomes the microcrack nuclear core and the macroscopic fracture growth and the connection way, as shown in Figure 6 arrow 1 and 2. The facture morphology is dimpled fracture organization, and deep dimpled fracture distributes evenly. Thus it can be seen that the toughness property of the grade X100 pipeline is very well under normal temperature condition.

\section{Discussion}

Correspondingly, the microstructure transformation was investigated around the plastic deformation; it is shown in
Figure 7. Before the plastic deformation, the ferrite plank (see Figure $3(\mathrm{a})$ ) is tiny and staggered mutually board strip constitute. The tiny M/A constitute is distributed on the plank boundary, which size is about $50 \mathrm{~nm}$ or even smaller. It can enhance substrate organization tensile and toughness. A large number of high density dislocation tangle distributed in the ferrite plank internal, which improved remarkably tensiles strength of the grade X100 pipeline. This kind of tangled or the existence node's dislocated grid configuration is advantageous to the dislocation stabilization and maintains high dislocation density [12-15]. The ferrite plank (length) the axial ratio approximately is $3: 1$. 


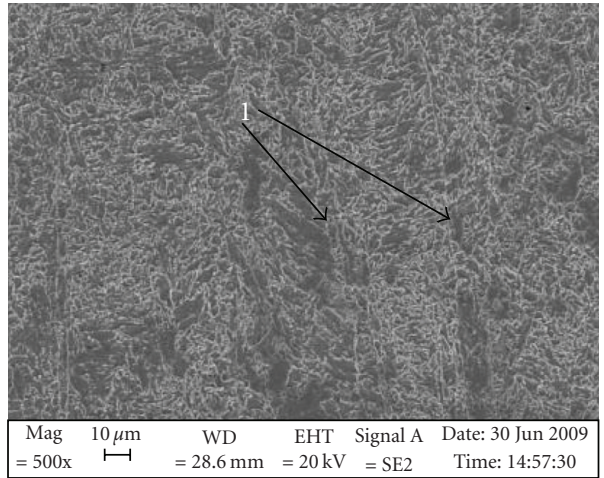

(a)

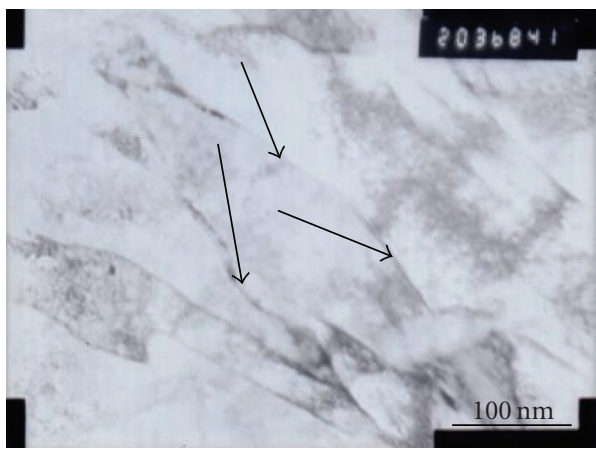

(c)

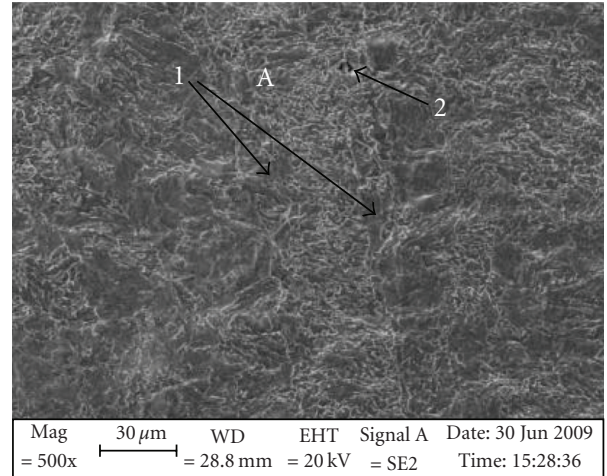

(b)

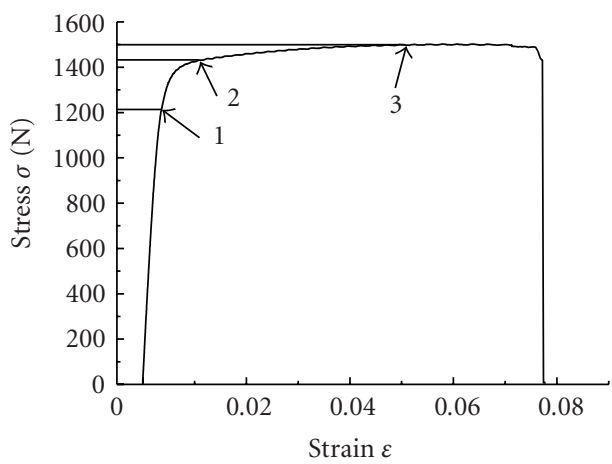

(d)

FIGURE 4: SEM and TEM pictures of granular bainite microstructure transformation (a) original, (b), and (c) after tensile, and (d) stressstrain curve.

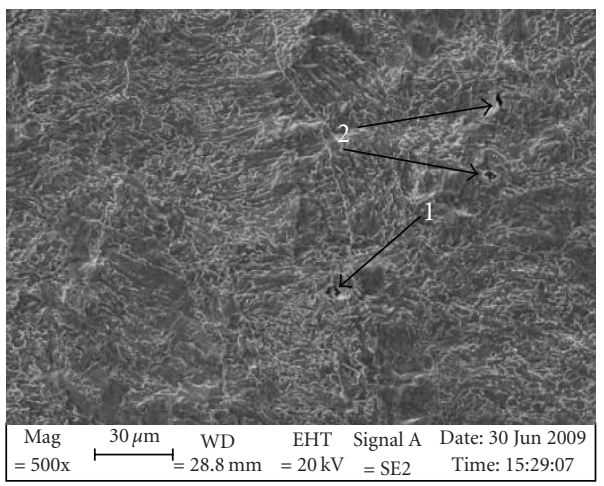

(a)

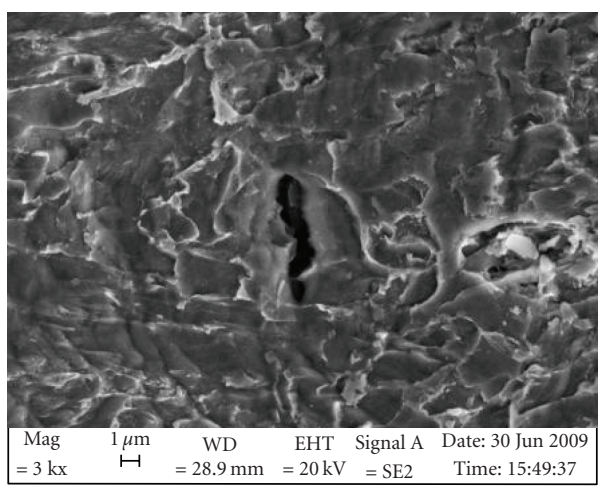

(b)

FIGURE 5: Microcrack formation during stretches process (a) and enlargement picture (b).

After plastic deformation, the high density dislocation accumulated gradually, reticulated in ferrite plank, or clustered around the M/A constitute on the plank boundary, which divided the entire ferrite plank into small regions, as shown in Figure 7(a). With plastic deformation increase, the dislocated grid formed gradually subboundary in the plank, in arrow 1 of Figure 7(b). Gradually, the straight plank boundary becomes flexural even extended along plastic deformation direction, and the previous plank bundle disappears gradually. Furthermore, since the M/A constitute possessed high strength and was not easily deformed, the high intensity dislocation formed during the deformation process gathers easily at its periphery and creates stress concentration; it forms the subboundary and plank boundary gradually, see Figure 7(b) arrow 2. Even in certain defective areas especially inclusion area, the dislocation intertwines to cause the stress concentration to become the microcrack nucleating center, in Figure 7(c) the arrow place.

Figure 8 is microscopic orientation and the corresponding ODF picture under original and after the tensile 


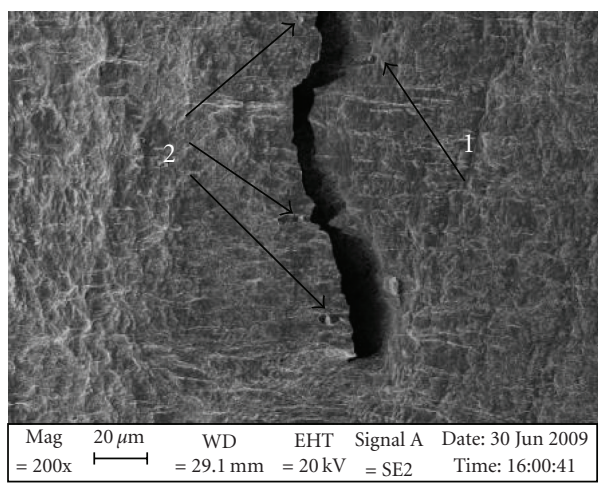

(a)

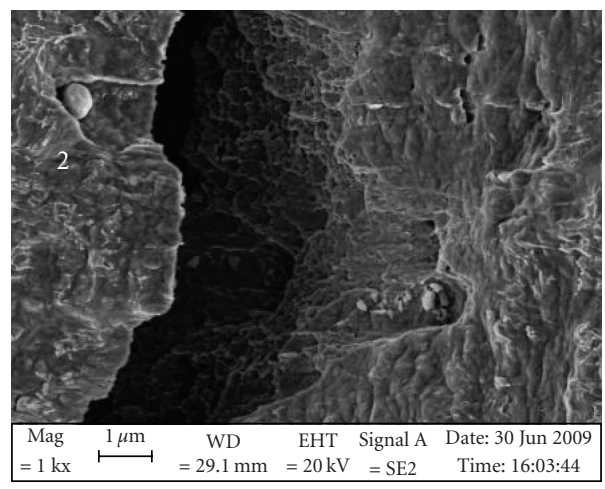

(b)

FIgURE 6: Macro-crack formation and magnified picture after the stretches.

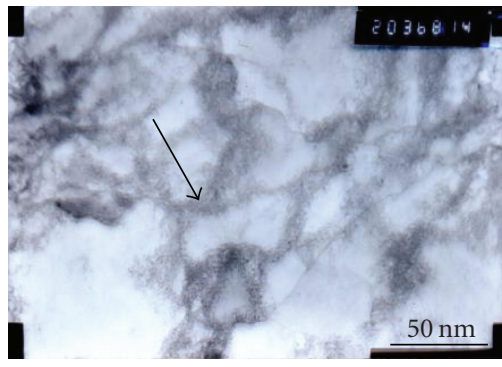

(a)

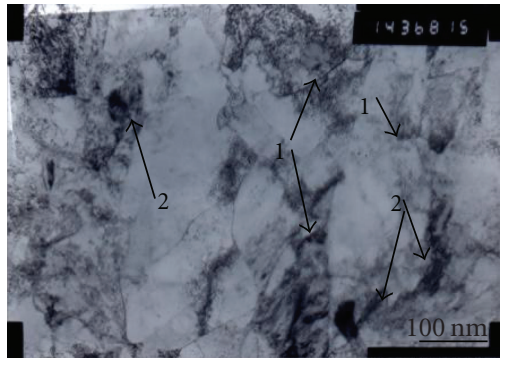

(b)

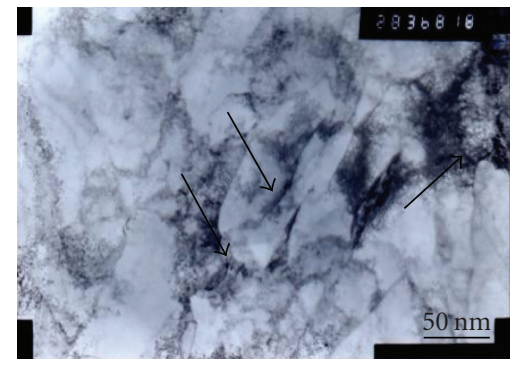

(c)

FIgURE 7: TEM pictures of grade X100 pipelines microstructure after plastic deformation.
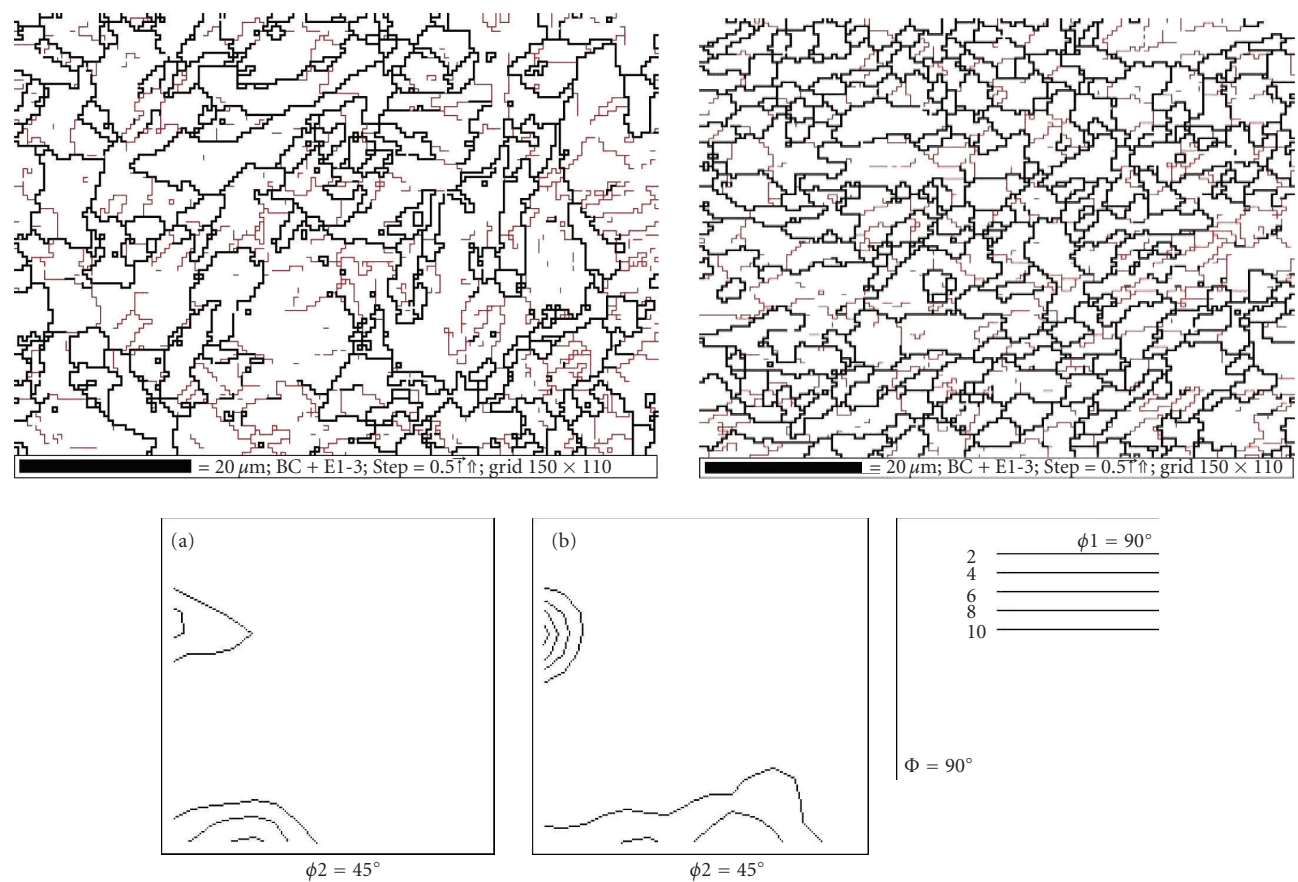

FIGURE 8: Microstructure orientation and texture component picture (a) original, (b) 5\% tensile strain. 
strain. The grain size (grain orientation angle is bigger than $15^{\circ}$, black streak in chart) is about $20 \mu \mathrm{m}$ before the tensile strain, and the massive mosaic structures were distributed in the crystal grain interior (see red streak in chart). The subgrain size approximately is $5 \sim 6 \mu \mathrm{m}$. After tensile deformation, the grain size, about $5 \sim 10 \mu \mathrm{m}$, reduces obviously. Some subgrain boundaries in the crystal grain formed the new crystal boundary gradually under tension stress's function. Obviously, the tensile strain causes the crystal grain deformation, and subgrain boundary forms the new crystal boundary during the stretch process. Before the stretch, the crystal orientation is quite centralized, mainly concentrates in the $\{110\}\langle 111\rangle$ direction, the orientation density approximately is 6 , and $\{112\}\langle 111\rangle$ direction has the weak texture orientation. After the stretch, the orientation density of $\{110\}\langle 111\rangle$ reduces, but which expands along the entire $\{110\}$ orientation range. The orientation density of $\{112\}\langle 111\rangle$ enhances and achieves above 8 [16-18].

According to the plastic deformation curve of grade $\mathrm{X} 100$ pipeline, it has high yield strength and yield/tensile ratio. Crystal refined and dislocation densities enhanced are mainly reinforcement manner of grade X100 high strength pipeline. Furthermore, because the microstructure of the grade X100 pipeline steel is composed of large number of small crystal grains, it was possessed high strength and not easily deformed. Therefore, when the plastic deformation happens, massive high density dislocations accumulated easily on the grain boundary and surrounding the M/A constitute it leads to stress concentration with ease. Only the prestrain is $5 \%$, and there is microcrack nucleated and expanded; it suggested that the ductility of the grade X100 pipeline possessed lots of tiny crystal grain is worse than that lower level pipeline steel, such as X70 or X80. Therefore, X100 pipeline is not good for laying through complicated regions.

\section{Conclusion}

The substrate organization of the X100 grade pipeline is mainly composed of the acicular ferrite and the granular bainite, and the grain size is small (crystal grain size 12 levels). Under in situ tensile condition, it can be observed that quasipolygon ferrite with low yield strength was deformed firstly. With plastic deformation increases, high dislocation density in the crystal grain accumulated gradually to form subboundary in the plank. Correspondingly, both acicular ferrite and granular bainite planks are deformed with deformation amount increases. Furthermore, there exists stress concentration surrounding both the inclusion and M/A constitutes; it becomes microcrack nuclear core, therefore, the size, quantity and distribution situation of the inclusion and M/A constitute are very important to the body organization plastic deformation ability. Before the deformation, the microscopic orientation concentrates in $\{110\}\langle 111\rangle$ direction; after the deformation, crystal orientation in $\{110\}$ and $\{112\}$ direction enhanced.

\section{Acknowledgments}

This work was supported by the National Postdoctoral Science Foundation of China (no. 18420006) and Special fund project (2008A-3005).

\section{References}

[1] H. Li, "Developing pulse and prospect of oil and gas transmission pipe," Welded Pipe, vol. 27, no. 6, pp. 111-120, 2004.

[2] H. Takuya, T. Eiji, M. Hiroshi, and A. Hitoshi, "Metallurgical design and development of X100/X120 high strength line pipe steel," in X100/X120 Level High Performance Pipeline Steel International High-Level Forum, pp. 136-144, 2007.

[3] V. Schwinn, S. Zajac, P. Fluess, and K.-H. Tacke, "Bainite steel plate for X100 and X120," in X100/X120 Level High Performance Pipeline Steel International High-Level Forum, pp. 251-260, 2007.

[4] C. Chao, "The development of grade X100 line pipe," Welded Pipe, vol. 22, no. 2, pp. 53-58, 1999.

[5] P. C. M. Rodrigues, E. V. Pereloma, and D. B. Santos, "Mechanical properities of an HSLA bainitic steel subjected to controlled rolling with accelerated cooling," Materials Science and Engineering A, vol. 283, no. 1-2, pp. 136-143, 2000.

[6] M. Okatsu, N. Ishikawa, S. Endo et al., "Development of high strength linepipes with excellent deformability," in Proceedings of the 24nd International Conference on Offshore Mechanics and Arctic Engineering (OMAE '05), pp. 63-70, Halkidiki, Greece, 2005.

[7] L. B. Wang, Y. Ren, P. C. Zhang, H. B. Wu, and D. Tang, "Experimental study on X100 pipeline steel," Iron \& Steel, vol. 43 , no. 1 , pp. 80-84, 2008.

[8] S. Okaguchi, M. Hamada, H. Makino et al., "Development and mechanical properties of X120 linepipe," in Proceedings of the 13th International Offshore and Polar Engineering Conference, pp. 36-42, Honolulu, Hawaii, USA, 2003.

[9] H.-G. Hillenbrand, K. Biermann, A. Liessem, C. J. Heckmann, and V. Schwinn, "Development of high strength material and pipe production technology for grade X120 line pipe," in Proceedings of the Biennial International Pipeline Conference (IPC '04), vol. 2, pp. 1743-1749, Calgary, Canada, 2004.

[10] Y. Terada, Y. Shinohara, T. Hara et al., "High strength linepipe with excellent HAZ toughness and deformability," in X100/X120 Level High Performance Pipeline Steel International High-Level Forum, pp. 313-332, 2007.

[11] M. Zhao, F. Xiao, Y. Shan, Y. Li, and K. Yang, "Microstructural characteristic and toughening of an ultralow carbon acicular ferrite pipeline steel," Acta Metallurgica Sinica, vol. 38, no. 3, pp. 283-287, 2002.

[12] A. Glover, J. Zhou, D. Horsley, N. Suzuki, S. Endo, and J.I. Takehara, "Design, application and installation of an X100 pipeline," in Proceedings of the 2nd International Conference on Offshore Mechanics and Arctic Engineering (OMAE '03), vol. 3, pp. 307-318, Cancun, Mexico, 2003.

[13] B. Hwang, Y. G. Kim, S. Lee, Y. M. Kim, N. J. Kim, and J. Y. Yoo, "Effective grain size and Charpy impact properties of hightoughness X70 pipeline steels," Metallurgical and Materials Transactions A, vol. 36, no. 8, pp. 2107-2114, 2005.

[14] B. Hwang, Y. M. Kim, S. Lee, N. J. Kim, and S. S. Ahn, "Correlation of microstructure and fracture properties of API X70 pipeline steels," Metallurgical and Materials Transactions A, vol. 36, no. 13, pp. 725-739, 2005. 
[15] B. Hwang, Y. G. Kim, S. Lee, N. J. Kim, and J. Y. Yoo, “Effects of microstructure on inverse fracture occurring during dropweight tear testing of high-toughness X70 pipeline steels," Metallurgical and Materials Transactions A, vol. 36, no. 2, pp. 371-387, 2005.

[16] H. Yu, "Influences of microstructure and texture on crack propagation path of X70 acicular ferrite pipeline steel," Journal of University of Science and Technology Beijing, vol. 15, no. 6, pp. 683-687, 2008.

[17] X. Ran, Q. Cai, D. Jiao et al., "Effects of process on microstructure and mechanical properties of X70 for strainbased design linepipe steel," Transactions of Materials and Heat Treatment, vol. 38, no. 2, pp. 38-42, 2009.

[18] P.-J. Zhang, X.-H. Liu, and G.-D. Wang, "EBSD study on an acicular ferrite/martensite dual-phase steel with high strength/low yield ratio," Journal of Northeastern University, vol. 28 , no. 1, pp. 57-59, 2007. 

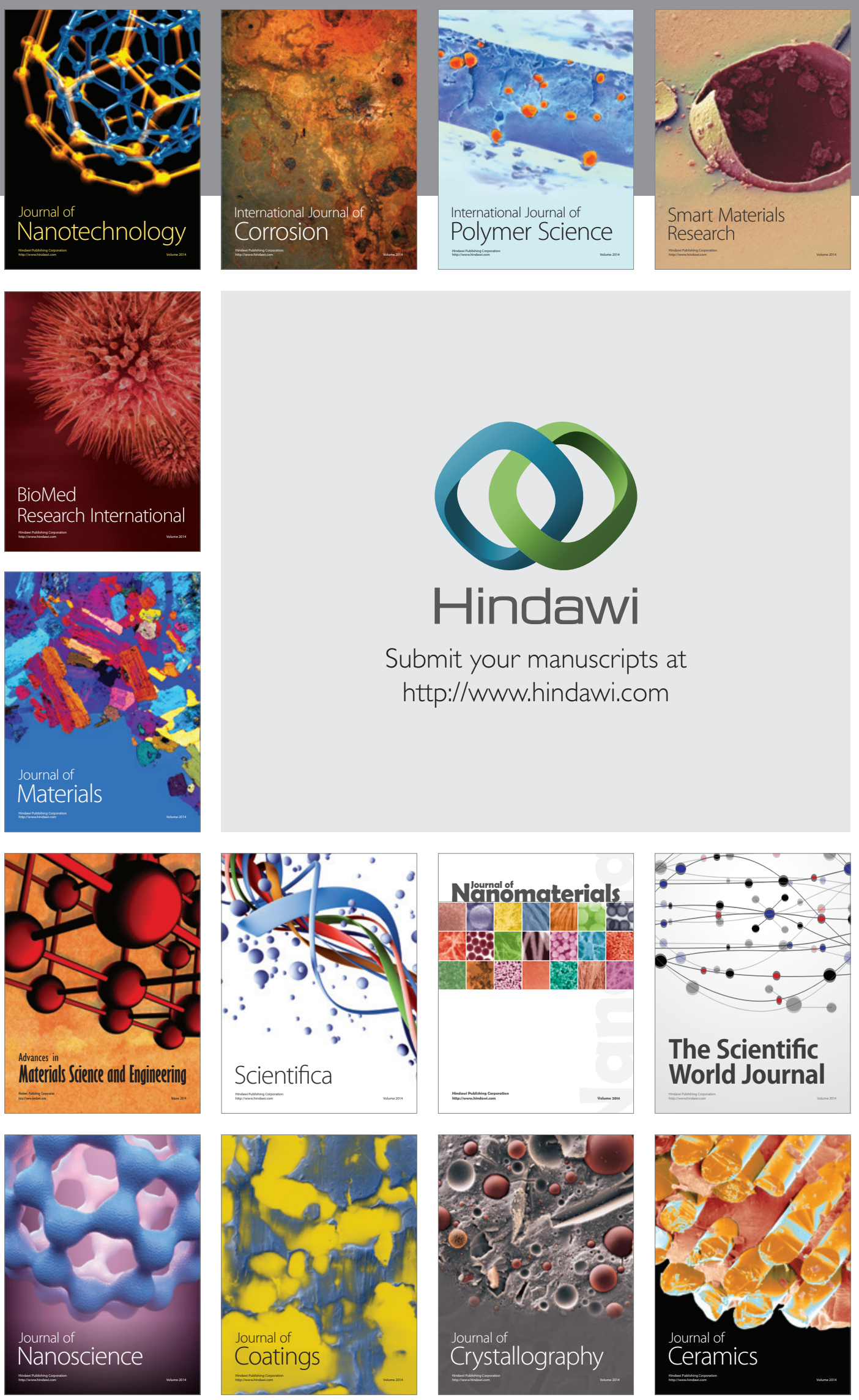

The Scientific World Journal

Submit your manuscripts at

http://www.hindawi.com

\section{World Journal}

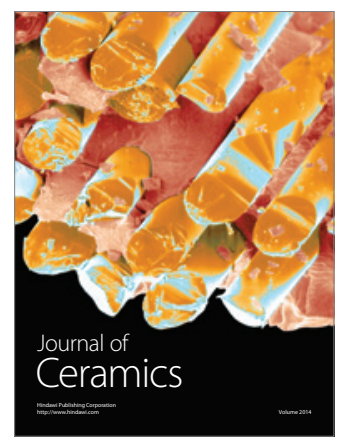

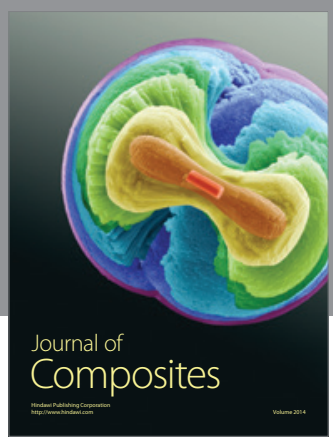
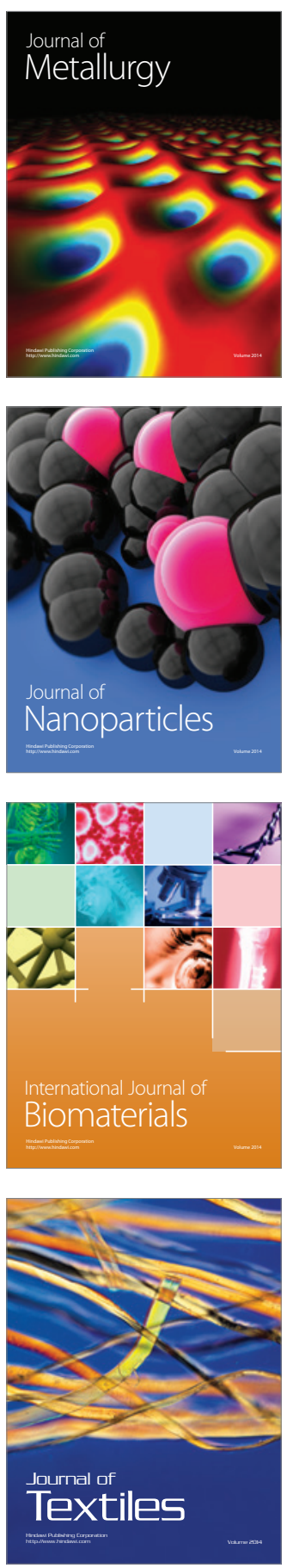